Original Research Article

\title{
Nutritional Status and Diet Quality in 7-10 Years Old School Going Children
}

Jain, Monika; Yadav, Deeksha; Singh, Vandana Chetna; and Chamoli, Ritushri

Department of Food Science and Nutrition, Banasthali Vidyapith, Banasthali, Rajasthan, India

Corresponding Author: drmonikajain2000@gmail.com

\section{A R T I C L E I N F O}

Received: 29 January 2018 | Accepted: 22 April 2018 | Published Online: 15 August 2018

DOI: $10.31786 / 09756272.18 .9 .1 .115$

EOI: 10.11208/essence.18.9.1.115

Article is an Open Access Publication.

This work is licensed under Attribution-Non Commercial 4.0 International

(https://creativecommons.org/licenses/by/4.0/)

CThe Authors (2018). Publishing Rights @ MANU_ICMANU \& ESSENCE-IJERC.

\section{A B S T R A C T}

Diet quality index is a measure of the quality of diet using a composite of recommendation regarding the consumption of foods and nutrients. This study was undertaken to assess the nutritional status and observe the diet quality and their association in 7-9 years old school going children. The sample comprised 120 boys and girls who were randomly selected from three schools. Background information was collected using self-designed questionnaire; socio economic status was assessed using Kuppuswamy's socioeconomic status scale. Anthropometric measurements included height and weight. Weight for age and height for age Z scores were calculated using WHO reference. Twenty four hour dietary recall was used to collect information regarding diet and nutrient intake; nutrient adequacy ratio and mean adequacy ratio were calculated. Healthy Eating Index-Canadian was used to assess diet quality of the subjects. According to weight for age $\mathrm{Z}$ score, 5.8\% were underweight and $0.83 \%$ were severely underweight. Nutrient adequacy was inadequate for energy and iron, and was 75\% higher than normal for fat. As per HEI-C diet quality of all the subjects was poor. Diet quality was not associated with anthropometric measurements of the subjects. Weak positive correlation was observed in nutrient intake and diet quality score, and no significant association was found between nutritional status and diet quality $(\mathrm{p}>0.05)$ and socio economic status and diet quality $(\mathrm{p}>0.0 .5)$ of children.

\section{K E Y W O R D S}

Anthropometry | Diet quality | Ealthy Eating Index | Nutritional status

\section{I T A T I O N}

Jain, Monika; Yadav, Deeksha; Singh, Vandana Chetna; and Chamoli, Ritushri (2018): Nutritional Status and Diet Quality in 7-10 Years Old School Going Children. ESSENCE Int. J. Env. Rehab. Conserv. IX (1): 45-53. 


\section{Introduction}

The school age period is nutritionally significant because this is the prime time to build up body stores of nutrients in preparation for rapid growth of adolescence. Better nutrition means stronger immune system, less illness, better health and productive community (Sati and Dahiya, 2012). More than 200 million school age children are stunted and under weight, about one billion school children will be growing up by 2020 with impaired physical and mental development. Population of school going children contributes to future man-power which can improve the socio economic condition of developing countries. Thus, their mental and physical well-being is of almost concern which can be achieved by adequate nutrition (Murugkar et al., 2013). Children who do not consume adequate amount of key nutrients, including calcium, potassium and vitamin $\mathrm{C}$ may be unable to work to their full potential at school (Nabarro et al., 2012). The quality of children's diet usually decline as they move from childhood to adolescence. Eating healthy is usually not a priority during childhood and poor eating pattern may thus add a risk for current and future health problems (OldewageTheron and Egal, 2010).

Since the beginning of the 21 st century, health practitioners, nutritionists and other scientists have been working to create tools to establish and measure diet quality, so that assessments can be made about whether the population is consuming 'good/healthy' (usually characterized as diets rich in fruit and vegetable content) or 'bad/ unhealthy' foods (usually defining diets containing a high proportion of high fat processed foods) and to facilitate comparisons across different groups. However, while it is considered 'relatively easy to assess diet quality in terms of consumption of particular food items, developing a single indicator for the measurement of overall diet quality is a more complex task' (Dubois et al., 2000).

Alongside evidence supporting the positive im- pact of individual food items, such as fruit and vegetables, on long-term health and well-being, it is increasingly acknowledged that 'it is the combination of foods that groups of individuals eat which comprise the overall diet, rather than the presence or absence of specific food items, that is ultimately of importance to nutritional health status (Pryer et al., 2001). As such, Mc-Naughton et al. (2008) argue that analyses of children's diets should examine not only individual food items or nutrients but also the types of food that that make up their whole diet. Researchers have conceptualized the measurement of overall diet quality in two broad ways. The first is concerned with which foods are eaten in combination (food patterns). The second involves considering the nutritional value of different foods relative to guidelines (Diet Quality Indexes).

In recent years there is a growing interest in nutritional epidemiology to analyze diet quality reflected by dietary patterns rather than single food or nutrients (Nair et al., 2015).The dietary pattern analysis approach implements the fact that foods are consumed in complex combinations and that the balance of the various aspects of the diet is crucial. The present study was carried out in this direction in order to assess the prevalence of stunting and underweight in 7-9 years old children and also to study their nutrients intake as well as diet quality.

\section{Materials and Methods}

The sample for the present study was collected from 3 schools of Bilaspur town of Rampur district of Uttar Pradesh, India. The sample consisted of 120 subjects of age 7-9 years including boys and girls. Selection was done using simple random sampling technique. Inclusion criteria were consent to participate in the study, regularity of attendance, age between 7-9 years. Exclusion criteria were suffering from fever or infection, ongoing medical treatment for any ailment and unavailability of parents to co operate in data collection. Due permission for data collection 
was obtained from the school authorities. Written informed consent was obtained from the parents of the selected students following the guidelines of ICMR (2010) for ethical considerations in human studies which are based on the Helsinki declaration. No invasive data was collected. The sample included 74 boys and 46 girls all belonging to the age group 7-9 years.

A self designed background information proforma was used to collect the required information from the subjects. The proforma was pretested and all the ambiguities in the questions and alternatives were noted. The proforma and its components were explained to small groups of subjects and then handed over to them and to fill in and get it approved by their parents. It was collected and checked at same time while collecting, by the investigator, the next day.

Socio-economic status was measured as a combination income and occupation of education (Darmon and Drewnowski, 2008). Kuppuswamy's socioeconomic status scale was used to classify socio-economic status of subjects. Kuppuswamy's socioeconomic status scale is an important tool in hospital and community based researches in India which was proposed in 1976. The revised version of the scale was used (Kumar et al., 2013).

Body weight was measured using bathroom scale accurate to $0.5 \mathrm{~kg}$ (Cole et al., 2007). Weight was taken in light clothing and was recorded to the nearest $0.5 \mathrm{~kg}$. Height was measured using anthropometric rod. Height of the subjects was recorded without foot wear and expressed to nearest $0.1 \mathrm{~cm} . \mathrm{Z}$ score of height- for- age and weightfor- age of the subjects was calculated by using Anthro Plus software and was classified using WHO references. Height- for- age Z score between -2SD to $-3 \mathrm{SD}$ was defined as stunting and below $-3 \mathrm{SD}$ as severe stunting. Weight- for- age $\mathrm{Z}$ score between $-2 \mathrm{SD}$ to $-3 \mathrm{SD}$ was defined as underweight and below $-3 \mathrm{SD}$ as severe underweight.

Dietary assessment of the subjects was carried out by 24 hour diet recall method (Thakur and Gautam, 2015). The daily nutrients intake per day by the subject was calculated with the help of Nutritive Value of Indian Foods (ICMR, 2010). The average daily intake of energy, protein, fat, calcium, iron and vitamin $\mathrm{C}$ were computed (NAR (Nutrient adequacy ratio) and MAR (Mean adequacy ratio) of the nutrient intake of the subjects was calculated. NAR is the ratio of a subject's nutrient intake to the estimated average requirement given by national guidelines on nutrient intakes. MAR was used as a composite indicator for micronutrient adequacy. It was calculated as the sum of NAR for all calculated nutrient divided by the number of nutrients calculated and expressed as a percentage.

Healthy Eating Index- Canadian (HEI-C), 2009 was used for the assessment of diet quality. HEI(2009) scores were estimated using 1 day of dietary intake data collected from subjects. The HEI$\mathrm{C}$ measures the intake of dietary components and provides a single score out of possible 100 points. A diet with a score $>80$ is considered "good", "one with a score of 50-80 is considered "needs improvements", and one with a score of $\leq 50$ is considered "poor". Each component contributes equally to the overall score.

Mean and standard deviation were descriptive statistics used in this study. Karl Pearson's coefficient ( $r$ ) of correlation was calculated to describe the degree of correlation between two series so as to know whether there is a positive or negative correlation between the given two series of data.

\section{Results}

The mean of age of the subjects was 8.83 years. Maximum subjects were from lower (36.66\%) and middle $(35.00 \%)$ income group followed by upper middle and upper income groups. All parents were literate and educated out of which nearly $43.32 \%$ were graduate, Fathers of nearly $38.33 \%$ children were farmers followed by businessmen (31.66\%). Remaining were in salaried jobs and none was unemployed. Mothers of $87.50 \%$ children were not working outside. Regarding food habits, majority of subjects were lacto vegetarian $(84.16 \%)$ and $10.83 \%$ were non vegetarian. Nuclear family trend was predominantly observed. 
The mean \pm SD weight of all the subjects was found to be $29.0 \pm 7.15 \mathrm{~kg}$. At age of 7-9 years, standard body weight is $25.1 \mathrm{~kg}$ (ICMR, 2010). Weight for age is an index of the adequacy of child's nutrition to support growth. According to weight- for- age $\mathrm{Z}$ score, $77 \%$ subjects were found to be normal (above -1SD) and $43 \%$ subjects were found to be under weight (below -2SD) and only one subject was categorized as severely underweight (below 3SD). The range of the height of the subjects varied from $123 \mathrm{~cm}$ to $153 \mathrm{~cm}$. The mean height $(\mathrm{cm})$ was found to be $135.0 \pm 8.20 \mathrm{~cm}$. According to height- for- age $\mathrm{Z}$ score, all subjects were normal (above -1SD). The mean daily intake of energy and iron were lower than recommended dietary allowances (RDA) as is evident from table 1. Most of the subjects were consuming energy between 1200 to $1500 \mathrm{kcal}$ per day, however, the lowest consumption reported was $900 \mathrm{kcal}$ per day. The iron intake of most of the subjects was $10 \mathrm{mg} /$ day. Mean intake of protein was higher while intakes were appropriate for calcium and vitamin $C$ when compared with respective RDAs. The range of calcium consumption was wide, between 170 to 1000 $\mathrm{mg}$ reported values for a day. Daily intake of vitamin $\mathrm{C}$ ranged between 24 to $46 \mathrm{mg} /$ day. Meeting the energy and nutrients needs between 77 to 100 per cent of RDA are considered adequate, therefore; the cut off for NAR is taken as 0.77. NAR was adequate for protein, calcium and vitamin $C$, inadequate for energy and iron, and was considerably above the desirable limit for fat. The mean adequacy ratio was found to be 0.99 which reflects overall adequacy of the nutrients in the diet.

Diet quality index is measure of the quality of diet using a composite of recommendation regarding the consumption of food and nutrient. Healthy eating index measures intake of nine dietary components (grains, vegetables/fruits, milk, meat, other, total fat, saturated fat, cholesterol, variety) to provide a single score out of a possible 100 point. In present study highest score attained by the subjects was 40 , but small number of subjects scored 40 , and the mean $\pm \mathrm{SD}$ score of all the subjects was 22.91 \pm 6.9 . More than half $(54 \%)$ of the subjects scored 20 points and nearly one third (32\%) sub- jects had overall 30 as a score. Score 10 was attained by $12 \%$ subjects whereas only $2 \%$ attained 40 as overall HEI-C score which is also much below the desired score of 80 . Thus diet quality of all subjects was classed as "poor". There was very weak positive correlation between energy intake and diet quality score $(\mathrm{r}=0.089)$, protein intake and diet quality score $(r=0.030)$, calcium intake and diet quality score $(\mathrm{r}=0.050)$, iron intake and diet quality score $(\mathrm{r}=0.005)$, and vitamin $\mathrm{C}$ intake and diet quality score $(\mathrm{r}=0.026)$, and a weak negative correlation was found between fat intake and diet quality score.

It was concluded that the nutritional status of the children is appropriate for their age group and prevalence of malnutrition is much below the national levels. While protein intake is sufficient general diets are low in energy and iron. Diet lacks variety, is high in fat and overall diet quality is poor.

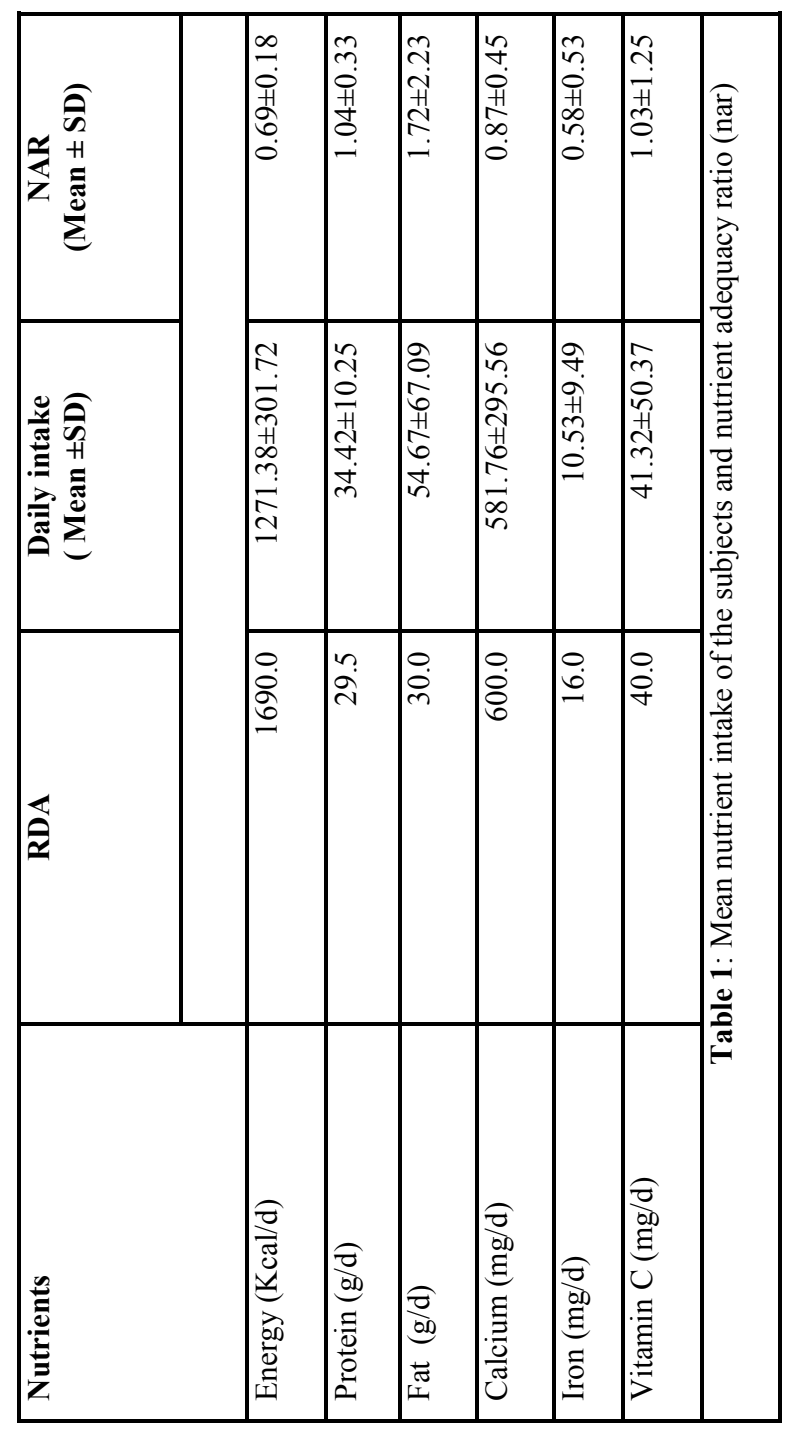




\section{Discussion}

In India the monthly average income, according to Centre for Monitoring Indian Economy, 2015 (2018) is 13,262 Rs. The observed trend in our study was in line with the national standards. Surveys conducted by FAO and USDA estimates that 20 to $42 \%$ of Indians are being vegetarian (Devi et al., 2014). The predominant food habit observed in this study was vegetarianism. It has been observed in a study of Soni and Katoch (2014) that maximum numbers of families were nuclear $(63 \%$ of rural and $79 \%$ of urban blocks) as compared to joint families (47\% rural $21 \%$ of urban blocks) of 7 -9 years old children of Himachal Pradesh. Contrary to this, a nuclear family trend of 3 to 5 members was observed in our study. Shah et al., (2003) concluded that children of non working mothers have better nutritional status than children of working mothers, possibly due to more time for caring of children, so the busy time schedule of working mothers adversely affects the nutritional status of children. This could be the explanation of optimal nutritional status of children who were a part of our study. Mukuria et al., (2005) concluded that the pattern of declining incidences of stunting by mother's education in Cambodia is consistent with patterns observed in many other developing countries. El-Sabely et al., (2013) concluded that there were highly significant difference was found between parents of the two study groups; parents of private school students had higher educational levels than parents of the public school.

Chowdhary et al., (2008) reported that prevalence of moderate and severe stunting, 9.73\% and $4.17 \%$ respectively among the age group of 5-12 years. In the study Shivaprakash and Joseph (2014) overall prevalence of underweight in the studied school children was $30.3 \%$ and it was seen more commonly in the age of 6-7 years boys.

Handa et al., (2008) reported that energy intake of 7-10 years old children was comparatively less than the recommended dietary allowances, mean intake was $1055.67 \pm 321$ in 7-8 years of age, $1113.96 \pm 244.77$ in $8-9$ years of age, and $1223.81 \pm 388.69$ in girls and $1191.13 \pm 381.25$ in boys of 9-10 years of age. Agrahar (2005) re- ported to have lower protein intake of $33.48 \mathrm{gm}$ which is lower than RDA in 7-12 year of age. Soni and Katoch (2014) also reported daily mean intake of fat by 7-9 years old school going children was $27.00 \pm 1.00$ in rural and $26.72 \pm 1.25$ in urban blocks. Chauhan (2001) reported a lower mean intake of calcium in the study group of age 7-9year i,e.,335.46 \pm 98.78 . Soni and Katoch (2014) reported that daily mean intake of iron by the 7-9 years old school going children of rural and urban was $8.32 \pm 0.5$ and $8.73 \pm 0.59$, respectively which was lower than the RDA and it was found to be due to less food intake especially green leafy vegetables in their diet. Neelam (2002) reported that intake of vitamin $\mathrm{C}$ by 7-10 year old school going children was $94.43 \pm 10.74$ which was higher than the RDA. Rastogi and Thakur (2014) concluded that nutrient adequacy ratio of energy, protein was found to be as compare to fat.

According to Woodruff et al. (2010), the mean HEI -C score among all the participants was $64.5 \pm 12.9$, $75 \%$ were falling into the needs improvement category, $13 \%$ had a poor diet quality and indicates that diet quality of only $12 \%$ of participant would be rated as good. According to Woodruff and Hanning (2010), the index score revealed that participants scored 74.5 using HEI-C 2009, and are rated in needs improvement category.

\section{Conclusion}

The diet quality of all children was unhealthy as computed by HEI-C but on the other hand not all children were malnourished. This suggests that HEI-C may not truly reflect the Indian diet quality and need to be modified for local use. HEI-C can provide the structure for the index but the questions have to be adopted as per the Indian dietary recommendations.

\section{Acknowledgement}

We are thankful to the subjects and school staff for helping at the time of data collection.

\section{References}

Agrahar-Murugkar, D. (2005): Nutritional status of Khasi school girl's in Meghalaya. Nutrition. 21 (4): 425-431.

Chauhan, V. (2001): Assessment of nutritional status of selected school children of Palampur 
region, M.Sc. Thesis, Department of Food Science and Nutrition, CSK HPKV, Palampur.

Chowdhury, S. D.; Chakraborty, T. and Ghosh, T. (2008): Prevalence of under nutrition in Santal children of Puruliya district, West Bengal. Indian Pediatr. 45(1): 43-46.

Cole, T. J.; Flegal, K. M.; Nicholls, D. and Jackson, A. A. (2007): Body mass index cut offs to define thinness in children and adolescents: International survey. BMJ. 335(7612): 194197.

Darmon, N. and Drewnowski, A. (2008): Does social class predict diet quality? Am. J. Clin. Nutr. 87(5): 1107-1117.

Devi, S. M.; Balachandar, V.; Lee, S. I. and Kim, I.H. (2014): An outline of meat consumption in the Indian population - A pilot review. Korean J. Food Sci. Anim. Resour. 34(4):507-515.

Dubois, L.; Girard, M. and Bergeron, N. (2000): The choice of a diet quality indicator to evaluate the nutritional health of populations. Public Health Nutr. 3(3): 357-365.

El-Sabely, A. A.; Tork, H. M. M. and Hussien, Y. E. (2013): Comparative study of nutritional status and dietary habits of children from public and private primary school in Zagazig city, Egypt. IOSR-JNHS. 3(1): 47-52.

Handa, R.; Ahamad, F.; Kesari, K. K. and Prasad, R. (2008): Assessment of nutritional status of 7 -10 years school going children of Allahabad district: A review. Middle East J. Sci. Res. 3 (3): 109-15

ICMR (2010): Nutrient Requirements and Recommended Dietary Allowance for Indians. A Report of the Expert Group of the Indian Council of Medical Research, New Delhi.

Kumar, B. P. R.; Dudala, S. R. and Rao, A. R. (2013): Kuppuswamy's socio economic status scales a version of economic parameter. Int. J. Res. Public Health. 1(1): 2 -4.

Vyas, M. (2018): Household income averaged Rs. 39,786 in September 2015 quarter. Center for Monitoring Indian Economy Pvt. Ltd. Available from: https://cmie.com/kommon/bin/ sr.php?kall=warticle \& dt $=2016-07-04 \%$ 2013:45:29\&msec $=170$
McNaughton, S. A.; Ball, K.; Crawford, D. and Mishra, G. D. (2008): An index of diet and eating patterns is valid measure of diet quality in an Australian population. J. Nutr. 138(1): 86 $-93$.

Mukuria, A.; Cushing, J. and Sangha, J. (2005): Nutritional status of children: Results from the demographic and health surveys 1994-2001. DHS Comparative Reports No. 10. Calverton, Maryland, USA: ORC Macro.

Murugkar, D. A.; Gulati, P. and Gupta, C. (2013): Nutritional status of school going children (6-9 years) in rural area of Bhopal district (Madhya Pradesh), India. Int. J. Food Nutri. Sci. 2(4): 61-67.

Nabarro, D.; Menon, P.; Ruel, M. and Yosef, S. (2012): SUN: A global movement to accelerate progress in reducing maternal and child undernutrition. Focus 19. Brief 9.Available from:file://C:/Users/admin/Downloads/ focus19_09.pdf

Nair, M. K.; Augustine, L. F. and Konapur, A. (2015): Food-based interventions to modify diet quality and diversity to address multiple micronutrient deficiency. Front. Public Health. 3: 277. doi: 10.3389/fpubh.2015.00277.

Neelam (2002): Assessment of Nutritional Status of selected school children of two selected blocks of Chamba District. M.Sc. Thesis, Department of Food Science and Nutrition, CSK HPKV, Palampur.

Oldewage-Theron, W. H. and Egal, A. A. (2010): Nutrition knowledge and nutritional status of primary school children in QwaQwa. S. Afr. J. Clin. Nutr. 23(3): 149-154.

Pryer, J. A., Cook, A. and Shetty, P. (2001): Identification of groups who reports similar patterns of diet among a representative national sample of British adults aged 65 years of age or more. Public Health Nutr. 4(3): 787-795.

Rastogi, M. and Thakur, N. (2014): Assessing calories intake and major nutrients of Moradabad school going children. Int. J. Food Nutr. Sci. 3(3): 40-43.

Sati, V. and Dahiya, S. (2012): Nutritional assessment of rural school-going children (7-9years) 
of Hisar district, Haryana. Sci. Rep. 1(7): 363. doi: 10.4172/ scientificreports.363.

Shah, S. M.; Selwyn, B. J.; Luby, S.; Merchant, A. and Bano, R. (2003): Prevalence and correlates of stunting among children in rural Pakistan. Pediatr. Int. 45(1): 49-53.

Shivaprakash, N. C. and Joseph, R. B. (2014): Nutritional status of rural school-going children (6 -12 years) of Mandya district, Karnataka. Int. J. Sci. Stud. 2(2): 39-43.

Soni, R. P. and Katoch, M. (2014): Dietary adequacy of school going children in selected areas of Himachal Pradesh. IOSR J. Humanit. Soc. Sci. 19(9): 85-90.

Thakur, R. and Gautam, R. K. (2015): Assessment of nutritional status among girls of 5-18 years of age of a central Indian city (Sagar). Hum. Biol. Rev. 4(4): 325-336.

Woodruff, S. J.; Hanning, R. M.; McGoldrick, K. and Brown, K. S. (2010): Healthy eating index$\mathrm{C}$ is positively associated with family dinner frequency among students in grade 6-8 from Southern Ontario, Canada. Eur. J. Clin. Nutr. 64(5): 454-460.

Woodruff, S. J. and Hanning, R. M. (2010): Development and implications of a revised Canadian healthy eating index (HEIC-2009). Public Health Nutr. 13(6): 820-825. 